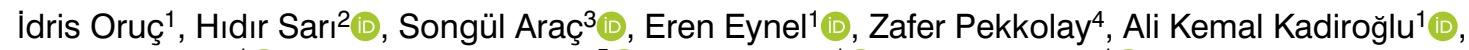

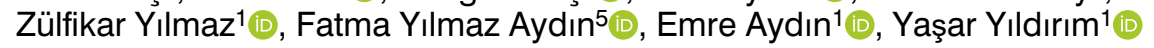

${ }^{1}$ Department of Nephrology — Internal Medicine, Faculty of Medicine, Dicle University, Diyarbakır, Turkey

${ }^{2}$ Faculty of Medicine, Department of Public Health, Dicle University, Diyarbakır, Turkey

${ }^{3}$ Department of Internal Medicine, Unıversity of Health Sciences, Diyarbakır Gazi Yaşargil Training and Research Hospital, Turkey

${ }^{4}$ Department of Endocrinology, Faculty of Medicine, Dicle University, Diyarbakır, Turkey

${ }^{5}$ Department of Internal Medicine, Faculty of Medicine, Dicle University, Diyarbakır, Turkey

\title{
Frequency and relationship of ABO blood groups in patients with nephrotic syndrome
}

\section{Corresponding author:}

İdris Oruç, Department of Nephrology - Internal Medicine, Faculty

of Medicine, Dicle University, 21280,

Diyarbakır, Turkey,

e-mail: dridris21@hotmail.com
Medical Research Journal 2021;

Volume 6, Number 4, 301-304

10.5603/MRJ.a2021.0050

Copyright $\odot 2021$ Via Medica

ISSN 2451-2591

e-ISSN 2451-4101

\begin{abstract}
Aim of the study: To investigate the frequency of $\mathrm{ABO}$ blood groups and the relationship between nephrotic syndrome (NS) and blood groups in patients with NS.

Material and methods: 199 patients with a diagnosis of NS and 200 healthy individuals, who applied to Dicle University Faculty of Medicine, Department of Nephrology between 2016 and 2020, and whose blood group information was in the records, were included in the study as the control group. This study was carried out retrospectively using data from the file registration system in our hospital.

Results: In the study, there were 199 patients: $52.8 \%(n=105)$ male and $47.2 \%(n=94)$ female and 200 healthy individuals: $47.5 \%$ male $(n=95) 52.5 \%$ female $(n=105)$. The mean age of the patients was 35.79 \pm 12.21 (min-max: 17-71), and the mean proteinuria was $7.08 \pm 4.33$ (min-max: 3.50-25.50). There was no difference between sick and healthy individuals in terms of age or sex $(p>0.05)$.

It was determined that $43.2 \%$ of the patients had blood group A, $26.1 \%$ blood group $0,25.1 \%$ blood group B, and $5.5 \%$ blood group AB. There was no significant difference between blood groups of patients with NS and individuals in the healthy group ( $p>0.05$ ). Membranous glomerulonephritis (MGN) (27.9\%) was most common in blood group A; FSGS was detected most frequently in blood groups B (46.0\%), $\mathrm{O}(28.8 \%)$, and $\mathrm{AB}(36.4 \%)$.

The most common cause of NS was focal segmental glomerulosclerosis (FSGS) in $31.2 \%$ ( $n=62$ ), and MGN was the second common cause in 19.1\% $(n=38)$, blood group B (37.1\%) in FSGS, blood group O (46.7\%) in systemic lupus erythematosus, MGN (63.2\%), IgA nephropathy (50\%), and MPGN (52.2\%) was found most frequently in blood group $A$.

Conclusions: We did not find a significant relationship between the blood group and NS in our study. Key words: nephrotic syndrome, ABO blood groups, proteinuria
\end{abstract}

Med Res J 2021; 6 (4): 301-304

\section{Introduction}

Nephrotic syndrome (NS) is the most common glomerular event and includes proteinuria over 3.5 grams, hyperlipidemia, edema, and hypoalbuminemia. NS occurs on average in three new cases per 100,000 people per year [1]. Inflammation is thought to be involved in the pathogenesis of NS due to the complement activation in NS, an increase in permeability factors, and an excellent response to nonsteroidal drugs [2].

The most common causes of NS are membranous nephropathy (24\%), minimal change disease (16\%), lupus $(14 \%)$, focal segmental glomerulosclerosis (FSGS) (12\%), membranoproliferative glomerulonephritis (7\%), amyloidosis (6\%), and IgA nephropathy (6\%) [3]. 
Discovered in the $19^{\text {th }}$ century and located on the erythrocyte surface, blood groups are determined by their antigenic structure. The system for their classification, developed by Karl Landsteiner, is called the ABO blood group system. In addition, another classification model known as the Rh system is also used regardless of antigenic structure [4]. Since blood group antigens are genetically encoded, these antigens can increase the incidence of some diseases and decrease the incidence of others. In a variety of studies, different diseases are associated with the ABO blood group, including coronary artery disease, depression, type 2 diabetes mellitus, chronic kidney failure, gastroduodenal ulcers, Crohn's disease, hepatitis B infection, Covid-19, thyroiditis, several cancer types, especially brain, breast, skin, pancreatic, and small cell lung cancers, and rheumatological diseases, such as Sistemic Lupus Eritematozus [5-12].

This study aimed to determine the frequency of $A B O$ blood groups and their relationships with NS in NS patients.

\section{Material and methods}

This study is a case-control study, and it was performed retrospectively using data from the file registration system of Dicle University Faculty of Medicine, Department of Nephrology. A total of 199 patients with NS who applied to our department between 2016 and 2020 and whose blood group information was recorded were included in the study. Patients with a diagnosis of NS were selected from individuals with proteinuria of $3.5 \mathrm{~g}$ or more in 24-hour urine and whose pathological diagnosis was confirmed by renal biopsy. The amount of proteinuria was measured in the 24-hour urine using a spectrophotometric method. For the control group, 200 healthy individuals who were similar to the NS patients in terms of age and sex, did not have chronic diseases and had blood group information recorded were included in the study. This study was approved by the university ethics committee (permit No. 2020/310).

\section{Statistical analysis}

The data were analyzed using SPSS statistical software. The normal distribution of the data was evaluated using a Kolmogorov-Smirnov test. Among the numerical variables, those with a normal distribution were shown as mean $(X) \pm$ standard deviation. Since the parametric assumptions were not met, a Mann-Whitney $U$ test was used to compare the means of the 2 independent groups. A chi-square test was used to compare the categorical data. If $p<0.05$ as a result of the analysis, the difference was considered statistically significant.
Table 1. Sex and blood group comparison of patients with nephrotic syndrome and the control group

\begin{tabular}{lccccc}
\hline & \multicolumn{2}{c}{ Patient } & \multicolumn{2}{c}{ Healthy } & P-value \\
\hline & $\mathbf{n}$ & $\%$ & $\mathbf{n}$ & $\%$ & \\
\hline Sex & & & & & \\
Male & 105 & 52.8 & 95 & 47.5 & $>0.05$ \\
Female & 94 & 47.2 & 105 & 52.5 & \\
Blood group & & & & & \\
A & 86 & 43.2 & 73 & 36.5 & $>0.05$ \\
0 & 52 & 26.1 & 67 & 33.5 & \\
B & 50 & 25.1 & 46 & 23.0 & \\
AB & 11 & 5.5 & 14 & 7.0 & \\
Total & 199 & $\mathbf{1 0 0}$ & $\mathbf{2 0 0}$ & $\mathbf{1 0 0}$ & \\
\hline & & & & &
\end{tabular}

$p>0.05$ the difference is not significant

\section{Results}

There were 199 NS patients: $52.8 \%(n=105)$ male and $47.2 \%(n=94)$ female, and 200 healthy individuals: $47.5 \%(n=95)$ male and $52.5 \%(n=105)$ female included in this study. The mean age of the NS patients was $35.79 \pm 12.21$ (min-max: 17-71). Mean proteinuria was $7.08 \pm 4.33$ (min-max: 3.50-25.50). The mean age of the healthy group was $37.13 \pm 14.14$ (min-max: 16-74). There were no significant differences between the sick and healthy individuals in terms of age or sex $(p>0.05)$.

It was determined that the patients' blood group distribution was $43.2 \%$ with group A, $26.1 \%$ with group $O, 25.1 \%$ with group $B$, and $5.5 \%$ with group $A B$. There were no significant differences between blood groups of the patients with NS and the individuals in the healthy group $(p>0.05)$ (Tab. 1).

The most common cause of NS was FSGS, found in $31.2 \%(n=62)$ of patients, while membranous glomerulonephritis (MGN) was the second most common and found in $19.1 \%(n=38)$ of patients. MGN $(27.9 \%)$ was the most common cause of NS for those with blood group A while FSGS (23.3\%) was detected as most the frequent cause for those with blood groups: $\mathrm{B}(46.0 \%)$, $\mathrm{O}(28.8 \%)$, and $\mathrm{AB}(36.4 \%)$.

The blood group found most frequently in FSGS was B (37.1\%) while blood group O was found most often in systemic lupus erythematosus (46.7\%), and blood group A was found most frequently in MGN (63.2\%), IgA nephropathy (50\%), and MPGN (52.2\%) (Tab. 2).

\section{Discussion}

To date, numerous studies have been published on the relationship between blood type and disease [5-7]. 
Table 2. Subtypes of patients with nephrotic syndrome according to blood groups

\begin{tabular}{|c|c|c|c|c|c|c|c|c|c|c|}
\hline \multirow[t]{2}{*}{ Nephrotic syndrome } & \multicolumn{2}{|c|}{ A } & \multicolumn{2}{|c|}{ B } & \multicolumn{2}{|c|}{0} & \multicolumn{2}{|c|}{ AB } & \multicolumn{2}{|c|}{ Total } \\
\hline & $\mathbf{n}$ & $\%$ & $\mathbf{n}$ & $\%$ & $\mathbf{n}$ & $\%$ & $\mathbf{n}$ & $\%$ & $\mathbf{n}$ & $\% \star \star *$ \\
\hline Focal segmental glomerulosclerosis & 20 & 32.3 & 23 & 37.1 & 15 & 24.2 & 4 & 6.5 & 62 & 31.2 \\
\hline Membranous glomerulonephritis & 24 & 63.2 & 2 & 5.3 & 9 & 23.7 & 3 & 7.9 & 38 & 19.1 \\
\hline Immune globulin A nephropathy & 14 & 50.0 & 8 & 28.6 & 5 & 17.9 & 1 & 3.6 & 28 & 14.1 \\
\hline Membranoproliferative glomerulonephritis & 12 & 52.2 & 3 & 13.0 & 7 & 30.4 & 1 & 4.3 & 23 & 11.6 \\
\hline Minimal change disease & 9 & 81.8 & 1 & 9.1 & 1 & 9.1 & 0 & 0.0 & 11 & 5.5 \\
\hline Systemic lupus erythematosus & 3 & 20.0 & 4 & 26.7 & 7 & 46.7 & 1 & 6.7 & 15 & 7.5 \\
\hline Other* & 2 & 11.1 & 8 & 44.4 & 7 & 38.9 & 1 & 5.6 & 18 & 9.0 \\
\hline Diabetic nephropathy & 2 & 50.0 & 1 & 25.0 & 1 & 25.0 & 0 & 0.0 & 4 & 2.0 \\
\hline Total* & 86 & 43.2 & 50 & 25.1 & 52 & 26.1 & 11 & 5.5 & 199 & 100.0 \\
\hline
\end{tabular}

*Acute tubular interstitial nephritis (6), chronic tubular interstitial nephritis (7), amyloidosis (5); ${ }^{\star \star C o l u m n ~ \% ~}$

A Canadian study from 1989, which included 8432 patients with end-stage renal disease, found that the ABO blood group was associated with disease mortality [13]. There have also been other studies on renal diseases, such as diabetic nephropathy, end-stage renal disease, and IgA nephropathy [14-16]. In all of these studies, it was suggested that some blood groups may give a predisposition to renal diseases while others may have a protective effect. Many hypotheses (inflammation, infection) have been suggested to explain the predisposition or protection associated with blood groups, and while a clear mechanism has not yet been revealed, they are still considered as possible causes. In other studies, however, a relationship between blood group and disease has not been confirmed. In a study by Abbas et al. [17], no correlation was found between $\mathrm{ABO}$ blood group antigens and kidney function tests.

In a study by Alhawary et al. [18], all blood groups: A (45.7\%), O (30.4\%), B (17.3\%), and AB (6.6\%) were found in patients with renal failure. These findings are consistent with our study. In our study, no relationship was found between NS and the blood group. In addition, the most common cause of NS in our study was FSGS. Furthermore, the most frequent cause of NS was FSGS for blood group $B$, systemic lupus erythematosus for blood group $\mathrm{O}$, and MGN for blood group $\mathrm{A}$.

In a study by Wang et al. [19] on whether the ABO blood group is associated with galactose-deficient $\lg A 1$ (Gd-lgA1) in the progression of kidney disease in patients with IgA nephropathy, it was determined that IgA nephropathy patients with blood group $A$ have a higher risk of adverse outcomes than those with blood group $B$.

Some studies have shown that the $A B O$ blood group antigen enhances the overall inflammatory response. It has also been revealed that single nu- cleotide polymorphisms in the $\mathrm{ABO}$ locus increase the levels of TNF- $\alpha$ and soluble intercellular adhesion molecule-1 (ICAM-1), which are two important serum inflammation markers, and that increased expression of TNF- $\alpha$ causes inflammation [20-22].

Furthermore, the mechanisms of the association between the $\mathrm{ABO}$ blood group and inflammatory responses to infection have been partially revealed. $A$ and $B$ antigens can be considered as receptors for pathogens that affect host-pathogen interactions and disease susceptibility among individuals with different glycosylation profiles [23]. Genetic studies have revealed that $A B O$ blood type is an important genetic determinant of circulating glycoprotein levels, which are important in endothelial function and inflammation. These glycoproteins are composed of (sICAM-1) selectins, von Willebrand factor (VWF), thrombomodulin, and TNF- $\alpha[24,25]$.

Yang et al. [26] evaluated the relationship between the $A B O$ blood group and the progression of IgA nephropathy. In IgA nephropathy, patients with blood group $\mathrm{O}$ or $\mathrm{A}$ and an increased inflammation level were found to be associated with an increased risk of impaired renal function.

The limited number of case controls in our study and the fact that it was a retrospective study constitutes the limitation of our study. However, this study may give a better understanding of the physiopathology of NS and be beneficial for other researchers planning larger prospective studies.

To our knowledge, this is the first study to evaluate the relationship between NS and blood group. We planned this study to investigate if the $A B O$ blood group has a role in triggering inflammation that may affect the development of NS. However, we did not find a significant relationship between the blood group and NS in our study. 


\section{Conflict of interest: None.}

Funding: None.

\section{Ethical permission: All procedures performed in studies involving human participants were in accordance with the ethical standards.}

\section{References}

1. Braden G, Mulhern J, O'Shea M, et al. Changing incidence of glomerular diseases in adults. Am J Kidney Dis. 2000; 35(5): 878-883, doi: 10.1016/s0272-6386(00)70258-7, indexed in Pubmed: 10793022.

2. Eddy A, Symons J. Nephrotic syndrome in childhood. Lancet. 2003; 362(9384): 629-639, doi: 10.1016/s0140-6736(03)14184-0, indexed in Pubmed: 12944064.

3. Rivera F, López-Gómez JM, Pérez-García R, et al. Spanish Registry of Glomerulonephritis. Clinicopathologic correlations of renal pathology in Spain. Kidney Int. 2004; 66(3): 898-904, doi: 10.1111/j.1523-1755.2004.00833.x, indexed in Pubmed: 15327378.

4. Temel Medikal Genetik. Ankara Üniversitesi Tip Fakültesi Yayinlari, 430. Ankara, 1982

5. Arac E, Solmaz I, Akkoc H, et al. Association between the Rh blood group and the COVID-19 susceptibility. Int J Hematol Oncol. 2020 30(2): 81-86, doi: 10.4999/uhod.204247.

6. Song $C$, Leng J, Wang $L$, et al. ABO blood types and postpartum depression among Chinese women: a prospective cohor study in Tianjin, China. Women Health. 2018; 58(6): 685-698 doi: 10.1080/03630242.2017.1333077, indexed in Pubmed 28532261.

7. Celić D, Lipozenčić J, Kolarić B, et al. Association between blood group and nonmelanoma skin cancers (basal cell carcinoma and squamous cell carcinoma). Int J Environ Res Public Health. 2019; 16(13): 2267 doi: 10.3390/ijerph16132267, indexed in Pubmed: 31252537.

8. Li N, Xu M, Li CF, et al. Prognostic role of the ABO blood types in Chinese patients with curatively resected non-small cell lung cancer a retrospective analysis of 1601 cases at a single cancer center. Chin J Cancer. 2015; 34(10): 475-482, doi: 10.1186/s40880-015-0054-2, indexed in Pubmed: 26411553.

9. Teshome $Y$, Mekonen W, Birhanu $Y$, et al. The association between ABO blood group distribution and peptic ulcer disease: a cross-sectional study from Ethiopia. J Blood Med. 2019; 10: 193-197, doi: 10.2147/JBM.S209416, indexed in Pubmed: 31308778

10. Ben Q, Liu J, Wang W, et al. Association between ABO blood types and sporadic pancreatic neuroendocrine tumors in the Chinese Han population. Oncotarget. 2017; 8(33): 54799-54808, doi: 10.18632/oncotarget.18592, indexed in Pubmed: 28903383

11. Çildağ $S$, Kara $Y$, Şentürk $T$. $A B O$ blood groups and rheumatic diseases. Eur J Rheumatol. 2017; 4(4): 250-253, doi: 10.5152/eurjrheum.2017.17044, indexed in Pubmed: 29308278.
12. Cheng $Y$, Cheng $\mathrm{G}$, Chui $\mathrm{CH}$, et al. $\mathrm{ABO}$ blood group and susceptibility to severe acute respiratory syndrome. JAMA. 2005; 293(12): 1450-1451, doi: 10.1001/jama.293.12.1450-c, indexed in Pubmed: 15784866.

13. Hamed IA, Mandal AK, Parker D, et al. ABO blood groups and renal disease. Ann Clin Lab Sci. 1979; 9(6): 524-526, indexed in Pubmed: 518016.

14. Alanan U, Abbas A, Sulaiman I. Relationship between ABO blood group and end-stage renal disease in Latakia, Syria. Saudi J Kidney Dis Transpl. 2017; 28(2): 445, doi: 10.4103/1319-2442.202762, indexed in Pubmed: 28352039.

15. Voigtmann $B$, Burchardt $U$. ABO blood groups in patients with nephropathies. Z Gesamte Inn Med. 1991; 46(5): 156-159, indexed in Pubmed: 2068845.

16. Wolfe RA, Ashby VB, Milford EL, et al. Comparison of mortality in all patients on dialysis, patients on dialysis awaiting transplantation, and recipients of a first cadaveric transplant. N Engl J Med. 1999; 341(23): 1725-1730, doi: 10.1056/NEJM199912023412303, indexed in Pubmed: 10580071

17. Abbas $A O$, Hassan $F, A b d u l l a ~ M H$, et al. The relationship between $A B O$ blood group antigens and renal function test among chronic kidney disease patients in Khartoum state. Saudi J Biomed Res. 2019; 4(1): 33-36, doi: 10.21276/sjbr.2019.4.1.6.

18. Alhawary SY, Al-Abdallat ME, Alamro SAA, et al. Frequency of blood groups amonga sample of patientswith renal fallure at royal medical services. Eur Sci J. 2015; 11(33)

19. Wang $M, L v J$, Chen $P$, et al. Associations of $A B O$ blood type and galactose-deficient immunoglobulin A1 with adverse outcomes in patients with IgA nephropathy. Nephrol Dial Transplant. 2021; 36(2): 288-294, doi: 10.1093/ndt/gfz171, indexed in Pubmed: 31603230.

20. Paré G, Chasman DI, Kellogg M, et al. Novel association of ABO histo-blood group antigen with soluble ICAM-1: results of a genome-wide association study of 6,578 women. PLoS Genet. 2008; 4(7): e1000118, doi: 10.1371/journal.pgen.1000118, indexed in Pubmed: 18604267.

21. Melzer D, Perry JRB, Hernandez D, et al. A genome-wide association study identifies protein quantitative trait loci (pQTLs). PLoS Genet. 2008; 4(5): e1000072, doi: 10.1371/journal.pgen.1000072, indexed in Pubmed: 18464913

22. Park EJ, Lee JH, Yu GY, et al. Dietary and genetic obesity promote liver inflammation and tumorigenesis by enhancing IL-6 and TNF expression. Cell. 2010; 140(2): 197-208, doi: 10.1016/j.cell.2009.12.052, indexed in Pubmed: 20141834.

23. Yamamoto $F$, Cid E, Yamamoto $M$, et al. $A B O$ research in the modern era of genomics. Transfus Med Rev. 2012; 26(2): 103-118, doi: 10.1016/j.tmrv.2011.08.002, indexed in Pubmed: 21945157.

24. Paré G, Chasman DI, Kellogg M, et al. Novel association of ABO histo-blood group antigen with soluble ICAM-1: results of a genome-wide association study of 6,578 women. PLoS Genet. 2008; 4(7): e1000118, doi: 10.1371/journal.pgen.1000118, indexed in Pubmed: 18604267.

25. Franchini M, Capra F, Targher G, et al. Relationship between ABO blood group and von Willebrand factor levels: from biology to clinical implications. Thromb J. 2007; 5: 14, doi: 10.1186/1477-9560-5-14, indexed in Pubmed: 17894864

26. Yang M, Xie J, Ouyang Y, et al. ABO blood type is associated with renal outcomes in patients with IgA nephropathy. Oncotarget. 2017; 8(43): 73603-73612, doi: 10.18632/oncotarget.20701, indexed in Pubmed: 29088730 